\title{
A Model for Enhancing the Verbal Communication Skills for Physician-Patient Communication of Medical Students at the Medical University-Sofia Based on a Needs Analysis
}

\author{
Kristina Hristova Stoyanova ${ }^{1,}$, , Ekaterina Rumenova Hartmann ${ }^{1}$, Evgeni Gospodinov Ivanov ${ }^{1}$, \\ Alexandrina Tzecomirova Vodenitcharova ${ }^{1}$, Nikola Rumenov Georgiev ${ }^{1}$, \\ Bistra Dragomirova Dudeva ${ }^{2}$
}

${ }^{1}$ Faculty of Public Health, Medical University-Sofia, Sofia, Bulgaria

${ }^{2}$ Department of Language Training and Sports, Medical University-Sofia, Sofia, Bulgaria

Email address:

kristina.hristova@yahoo.com (K. H. Stoyanova), hartmannekaterina@gmail.com (E. R. Hartmann), evgeniivanov_@hotmail.com (E. G. Ivanov),al.vodenicharova@abv.bg (A. T. Vodenitcharova),nrgeorgiev@abv.bg (N. R. Georgiev), bistra_dudeva@yahoo.com (B. D. Dudeva)

${ }^{*}$ Corresponding author

\section{To cite this article:}

Kristina Hristova Stoyanova, Ekaterina Rumenova Hartmann, Evgeni Gospodinov Ivanov, Alexandrina Tzecomirova Vodenitcharova, Nikola Rumenov Georgiev, Bistra Dragomirova Dudeva. A Model for Enhancing the Verbal Communication Skills for Physician-Patient Communication of Medical Students at the Medical University-Sofia Based on a Needs Analysis. Education Journal. Vol. 8, No. 2, 2019, pp. 75-88. doi: 10.11648/j.edu.20190802.15

Received: February 11, 2019; Accepted: April 23, 2019; Published: May 23, 2019

\begin{abstract}
Enhancing future physicians' communication skills represents a central problem of medical education. Communication experts have reached consensus on the stages of medical communication, on a key set of communication skills, and helped decisions on the communication curricula of medical schools. Adequate language techniques for physicianpatient communication are proposed by the Clear writing and plain language campaign. However, a needs analysis is obligatory in planning and designing communication training for the concrete students. The present study is conducted with the medical students at the Medical University-Sofia, Bulgaria. The comparative analysis of the survey results of undergraduate and graduate respondents reveals students' growing understanding of the factors, problems and importance of physician-patient communication, increasing willingness and readiness to enhance verbal communication skills as well as a preference for the teaching methods of role play in a realistic context. To meet the medical students' needs, a Model for enhancing the verbal communication skills of future physicians has been proposed, based on the stages of medical communication and language techniques for the communication between medical professionals and patients. The Model is assessed by experts as an adequate tool to improve future physicians' communication skills and to help increase the quality of patient health care and patient satisfaction. The researchers recommend that the Model to enhance medical students' verbal communication skills should be included in the communication training curriculum of the Medical University-Sofia.
\end{abstract}

Keywords: Verbal Communication Skills, Needs Analysis, Medical Students

\section{Introduction}

Teaching communication for the purposes of the medical profession is a central problem of medical education. It can help medical students acquire skills and competences to communicate with patients because rapport with patients is an inseparable part of the treatment process.
The importance of the physician-patient communication is determined by its aim to achieve and maintain the health and well-being of individuals. It is essential to improve the communication and relationships between physicians and patients, their relatives and support systems, since medical specialists are often identified as superb professionals but deficient on communication skills [1]. Interpersonal and communication skills are identified as one of physicians' 
major professional competences [2]. Physicians' welldeveloped communicative competence is connected to a positive impact on patient co-operation and satisfaction, making informed decisions about medical procedures, improving health outcomes and reducing health care costs [1, 3]. Adequate physician-patient communication boosts patient compliance with the prescribed treatment and that compliance increases 1.62 times in case physicians get communication training [4]. Optimizing communication between doctors and patients is in line with the medical ethics requirements to safeguard patients' rights to access information [5-8]. Therefore, medical professionals are required to sophisticate their skills for interpersonal communication, effective listening, clear expression and readiness to cooperate with patients $[1,8]$. Communication training of physicians improves their practical competence for rapport with patients during consultations and supports their empathic behavior [9-11]. Recognizing the importance of communication training influences medical schools to review programs, teach and test medical students' communication skills.

Evidence of the importance of enhancing future physicians' communication skills [2, 4, 9, 11-13] has led to conscious efforts to seek consensus on the content of their communication training. Over the past thirty years a number of consensus statements on the content of communication curricula of medical schools were designed. Uncovering the logic of their recommendations and achievements in determining the content of the communication curriculum can lead to mapping the unresolved problems and areas for future research.

Already in the early 1990s, a group of experts in the fields of medicine, psychology and communications adopted the Toronto consensus statement, outlining the challenges and priorities of medical training with a focus on doctor-patient communication [14]. In Oxford in 1996 the International Conference on Teaching Communication in Medicine made a number of recommendations to develop and implement training and assessment programs. In 1998 the Health Conference organized by NIVEL, Netherlands' Institute for Primary Health Care, outlined some major recommendations such as the following: (1) teaching should define and help students to successfully carry out communication tasks, focused on the patient; (2) there must be a planned and coherent framework for teaching communication skills; (3) the development of communication teachers should be supported and adequately ensured [1].

A contemporary approach to communication curricula has been suggested by 'The Health Professions Core Communication Curriculum: objectives for undergraduate education in health care professions' (HPCCC), a recent consensus statement, developed by the the European Association for Communication in Healthcare (EACH), which summarizes the achievements of global and European ideas with regard to the goals and training of medical and health care professionals for communicating with patients [15]. In $2008 \mathrm{EACH}$ formed a working group of experts from
18 European countries, who compared and categorized the skills, outlined in the existing consensus statements (such as those from Toronto, Maastricht, Kalamazoo, the UK, Basel [14, 16-19]). Based on the comparison and their own research, EACH experts have worked out "The Health Professions Core Communication Curriculum: objectives for undergraduate education in health care professions", where the first section is Communication with Patients.

With regard to physician-patient communication, EACH core curriculum presents several types of objectives: core communication objectives (11 objectives); more detailed specific objectives, depending on context and situation: shaping of the relationship ( 2 objectives) and patient's perspective and health beliefs (3 objectives); objectives, related to the information ( 7 objectives) and those, related to reasoning and decision making, including situations of uncertainty (9 objectives). EACH consensus document has the advantages of a detailed enumeration, examination and analysis of communication skills from the different perspectives of the medical and health sciences and achieves an interdisciplinary approach. In order to assess the importance of each objective, EACH experts used the Delphi method.

An essential advantage of HPCCC is that different communicative, language, behavioral approaches were employed to choose and formulate the objectives and skills, comprehensively describing the medical communication situation. HPCCC uses the methodology of earlier consensus statements where communication skills are categorized according to the stages of communication during patient examination and treatment. Therefore, the specific skills, outlined in HPCCC, emphasize the context and specificity of medical communication situations. The influence of psychological and emotional factors in communication (HPCCC skills No 3, 7, 15, 27) as well as emergency situations and decision-making (HPCCC skills No. 24-32) have been taken into account [15].

EACH core curriculum contains certain verbal communication goals and skills to be developed, using language techniques. The core skills include the ability to maintain rapport (HPCCC skill No 3) and its smooth development from beginning to end (HPCCC skill No 1). The curriculum recognizes the key importance of verbal and non-verbal communication skills (HPCCC No 4, 6, 23), but links them only to one of the basic language skills, namely, active listening (HPCCC No 4). Other very relevant skills: speaking, reading and writing, are omitted. As to language techniques, one of them, the technique of questioning, is assessed as the most significant and is formulated separately (HPCCC skill No 5). The technique of the paraphrase is also mentioned. References to language are made mainly on the level of functional grammar and concern only some language functions such as summarizing, collecting and giving information, verbalizing emotional content. Although in the main goals of HPCCC some verbal communication skills are stated, albeit fragmented, the language techniques that can be used to create and support such skills are not exhaustively 
listed and systematized. Thus, the problem of what language techniques can be used to teach verbal communication skills to medical students has not been resolved yet, leaving a niche for further research.

The concrete dimensions of the problem of what language techniques for verbal communication to teach to medical students can be revealed on the basis of a needs analysis of the students to be taught. As the learner-centered approach has become a major aspect of contemporary education, European education policy identifies students' needs as a core component of education systems [20]. However, the Health Professions Core Communication Curriculum is based on the expertise of a great number of European medical communication teaching professionals, thus, lacking concrete educational context. Moreover, the needs, opinions and attitudes of medical students at the Medical University-Sofia, regarding physician-patient verbal communication, have not been surveyed recently, except for a needs analysis of these students' professional verbal communication in English, conducted in 2008 [21]. To conclude, designing a curriculum and adopting teaching methods and frameworks, such as a model to teach verbal communication skills at Medical University- Sofia, requires a needs analysis of the students studying there.

\subsection{Statement of the Problem}

Under ideal circumstances teaching medical students to acquire skills and competences for verbal communication with patients is to be based on the specificities and comprehensive description of physician-patient communication, of adequate verbal communication techniques, compatible with the medical communication situations, as well as on a needs analysis of the concrete opinions, desires, attitudes, habits of the medical students to be taught.

At present experts' consensus statements have worked out communication curricula for future medical professionals, which, however, lack a comprehensive account of the language techniques for verbal communication to be used. These techniques should be based on the specificity of medical communication so that a more comprehensive model for enhancing medical students' verbal skills for professional purposes is to be designed. Successful application of that model is plausible in case concrete medical students' learning needs and desires are met.

The present paper examines the relationship between the stages of physician-patient communication and the language techniques for that communication, on the one hand, and the concrete learning needs of the medical students at the specific medical school, on the other hand. Based on these relationships, a model for enhancing medical students' verbal communication skills is to be designed for use at the Medical University-Sofia.

\subsection{Objective of the Study}

i To identify a comprehensive and succinct description of the stages of physician-patient communication;

ii To determine what language techniques can be used to enhance medical students' verbal communication skills for physician-patient communication;

iii To analyze the learning needs, desires and attitudes of medical students at Medical University-Sofia;

iv To design a Model for enhancing the verbal communication skills for physician-patient communication of medical students at the Medical University-Sofia.

\subsection{Research Questions}

The following research questions were addressed and answered,

1. How can the stages of physician-patient communication be comprehensively and succinctly described?

2. What language techniques can be used to enhance medical students' verbal communication skills?

3. What are the concrete needs, opinions, desires and attitudes of the medical students at the Medical University - Sofia regarding their verbal communication skills?

4. What Model for enhancing medical students' verbal communication skills can be designed based on the comprehensive description of physician-patient communication, the language techniques and meeting concrete students' learning needs?

\section{Literary Review}

\subsection{Stages of Medical Communication as a Basis for the Model}

As stated above, the contemporary core curriculum, designed by the European Association for Communication in Healthcare $(E A C H)$, is based on the stages of medical communication. In this respect it drew on the achievements of previous consensus statements.

The consensus statement, worked out by a group of experts at Maastricht University, the Netherlands, analyzes the stages of medical communication and distinguishes three types of communication skills: general communication skills; skills, associated with each phase of medical treatment; skills, related to specific medical aspects [16]. General communication skills are connected to the study of patients' problems, the provision of information, the expression of empathy and emotions. A series of communication skills are linked to different phases of the visit to a physician: communicating during the initial phase of a medical consultation, following a medical request, making a diagnosis, patient management, and assessment of the overall treatment. Special attention is paid to those skills, related to pronounced medical aspects and necessary during the physician's visit and treatment, such as taking a history, carrying out a physical examination, making a diagnosis, prescribing treatment and managing the patient. This approach clearly links the physicians' communication with 
the stages of medical examination and treatment.

A comprehensive enumeration of the stages of medical communication has been proposed by the Kalamazoo consensus statement, worked out on the opinion of experts on medical communication. It focuses on identifying the elements of the communication with patients [17]. The experts have analyzed the basic elements of doctor-patient communication and identified seven main groups of communicative tasks/ skills, namely: 1) build the doctorpatient relationship; 2) open the discussion; 3) gather information; 4) understand the patient's perspective; 5) share information; 6) reach agreement on problems and plans; and 7) provide closure. Finally, one skill has been added, which refers to the flow of the entire communicative act, namely, overall managing rapport. The common elements of communication, identified at the conference, provide a useful framework for communication skills training [17].

The experts elaborated on the meaning of each of the tasks/skills. The first task, which aims at creating positive and effective relationships with the patient, is highlighted by experts as the ultimate goal of doctor-patient communication. The ability of physicians to open the discussion involves letting the patient talk and express fears, and creating a relationship of sincerity and honesty with the patient. The skills to collect information require asking enough questions to gather accurate and detailed information about the disease. Finally, all the necessary communication skills are summarized in one overarching skill, namely, successfully managing rapport from beginning to end. That last, allembracing task has been added to encompass communication during all stages of the medical examination. This creates certainty that no aspect or stage of communication with the patient will be overlooked in the medical students' training.

The Kalamazoo stages of medical communication were widely acknowledged as a solid foundation for developing communication skills. Further, the Basel consensus statement was also developed referring to the stages of medical communication, analyzing medical communication as a dialogue between communication participants, striving to achieve information, social and emotional goals [19]. The result was a more comprehensive enumeration of participants' communication skills.

As stated above, a major advantage of HPCCC, developed by the European Association for Communication in Healthcare, is the use of the stages of medical communication. To conclude, a series of consensus statements employs the stages of medical communication to identify the communication skills of medical students for rapport with patients, which proves these stages represent a comprehensive description of physician-patient communication and can become a basis for a model to enhance students' skills.

\subsection{Language Techniques for Verbal Communication as a Basis for the Model}

The language techniques for professional communication have been mainly studied in connection with teaching individual languages for specific professional purposes, as for example, teaching English for medical purposes. About thirty years ago researchers in medical English started studying different language mechanisms and since then, extensive knowledge has been amassed in regard to the linguistic application of various language techniques [22-27]. Later on, more sophisticated studies of genre and discourse focused on the use of certain linguistic characteristics, such as rhetorical features, conventional lexis, texts' information intensity, the importance of social context, etc. as well as conversational analyses of medical discourse practices [2831].

However, a wider view of the language techniques can be provided by existing research, relating to communication between professionals and laymen in general. Research efforts in this field have transformed into a comprehensive approach to verbal communication for professional purposes in the Clear writing campaign. It has summarized the major, most effective language techniques for communication between professionals and citizens and provides practical directions to optimizing that communication. The Clear writing campaign has been developed in connection with a European policy, which focuses on the use of some language techniques and tools to bridge the void in the knowledge and understanding of information between professionals and citizens. The campaign, an initiative of the European Commission and other European institutions, aims at creating texts, which are clear and easily understood and use plain language [32, 33, 34]. Initially, the purpose of the campaign was to assist in the translation of the various European languages, which could be improved if two conditions were met: first, the content of the original should be clearly communicated in the original language of the message and second, the translation should also clearly and understandably express the meaning of the original [35].

This campaign addresses the real problems of communication during the performance of professional duties and the communication of professionals with the general public. The Clear writing campaign is related to Council Directive 93/13 / EEC of 5 April 1993, which requires everyone within 'his trade, business or profession' to use 'plain, intelligible language' [36]. Research indicates that the more complex the content of the original text, the more important it is to apply the ideas of the Clear writing campaign $[37,38]$. During the campaign language techniques for clear and effective expression and communication (paraphrase, change the time frame, explore the consequences, give a concise presentation, find a counterexample, create an active attitude, turn to positive intentions, change the context, avoid or replace strange and complex words) have been elaborated [32-35, 39-45].

Each of these techniques has been implemented using various lexical and syntactic changes in the oral or written text. The paraphrase is a generalizing mechanism, which implies a logical, short, clear and tight structure of the oral or written text. Thus, paraphrasing involves many other specific techniques. The "creation of active attitude" can be applied 
through the predominant use of the active voice instead of the passive, as well as by using more verbs instead of the cumbersome nominalization. "Avoiding unfamiliar and complex words" involves the replacement of incomprehensible medical terminology, which can be achieved by two language techniques: by replacing the term with an everyday word or with a description. The "change of context" requires focusing on the recipient of the message and taking into account various parameters such as the patient's age, social status, educational level, gender as well as the severity, stage and prognosis of the disease.

Therefore, if the principles of plain and intelligible language are adhered to and the subsequently designed language techniques are used for promoting professional communication skills in higher education communication curricula, a favorable effect on communication between professionals and the audience can be achieved. Considering that medical and health care information is highly sophisticated, the communication training of medical students can strongly benefit from the language techniques, aiming at using a simple, clear and understandable language.

\subsection{Needs Analysis as an Initial Step in Designing Curricula}

The learner-centred approach to the teaching process has suggested a more profound understanding of the significance of learners' goals, opinions, attitudes and learning styles. Although recently the learner has increasingly been in the focus of designing programs and materials, research in the field of needs analysis has been developing for a few decades now. The first comprehensive study of needs analysis was outlined in Munby's book "Communicative Syllabus Design", which determined what a needs analysis should encompass [46]. The main element of Munby's model, the Communicative Needs Processor (CNP) identified needs by investigating the target situation and became known as Target Situation Analysis [47]. The advantage of the CNP was it gathered information on the learners' age, nationality and the present level of their command of the target language and thus, identified the communicative competences, which the learners were to acquire and master at the end of the teaching course. The disadvantage of the CNP was the data were fed into it by the teachers. Therefore, Hutchinson and Walters transformed the CNP parameters into questions to be answered by the learners [48]. To turn attention to the initial stage of communicative training, Richterich and Chancerel introduced Present Situation Analysis [49]. This type of analysis was further developed by Jordan, who focused on the deficiencies in the learners' knowledge and skills to be repaired [50], while Swales identified the environmental aspects, which impacted the learning process [51]. DudleyEvans and St. John elaborated on the importance of Means Analysis which aimed at revealing data about the cultural environment of the training course. As a result, DudleyEvans and St. John have summarized all these ideas in a concept of needs analysis, which includes all above mentioned aspects of needs analysis [52]. They maintain any needs analysis of a concrete group of learners is to be as exhaustive as possible in order to help determine teaching models, programs and materials.

A needs analysis of medical students at the Medical University-Sofia, regarding their physician-patient verbal communication skills, has not been conducted recently, except for a survey of these students' needs for professional verbal communication in English in 2008 [21]. For the purposes of the present study we used a questionnaire, adapting Dudley-Evans and St. John's comprehensive ideas about needs analysis. It has helped to reveal a rather detailed picture of the learning needs, opinions and attitudes of the medical students at the Medical University-Sofia

\section{Needs Analysis of the Medical Students at the Medical University-Sofia}

\subsection{Aim of the Study}

The aim of the survey is to reveal the medical students' needs, their level of willingness and attitudes to enhancing their verbal communication skills for physician-patient communication. For the purpose, we adopted a needs analysis approach.

\subsection{Materials and Methods}

For the 2015- 2017 needs analysis, conducted at the Medical University-Sofia, a questionnaire containing closedended questions was used. The survey indicators were: factors and problems of physician-patient communication, the importance and ways to improve verbal communication skills, need and willingness to increase communication skills through targeted training at the medical university, preferred learning methods used to enhance verbal communication skills, respondents' social and demographic characteristics such as age, gender, educational level, marital status.

The study population encompassed 495 students from the Medical Faculty of the Medical University-Sofia, divided into two groups. The first group of respondents comprised 291 first- and second- year students (hereafter called undergraduate students) for whom more mandatory and elective courses in professional communication are present in the curriculum. The second group is that of 204 fourth-, fifthand sixth- year students in medicine (hereafter called graduate students), who are to start practicing their profession. The surveyed students were randomly selected.

The groups of undergraduate and graduate students were analyzed in respect to their socio-demographic characteristics: age, gender, educational level, marital status. The respondents from each of the two groups were divided into three age groups: 18-21 years old, 22-26 years old, 27 to 36 years old. When students pass from one educational level into the next, their age naturally grows. Thus, the majority of undergraduates fall in the 18-21 year old group (96\%), while that of the graduates belongs in the 22-26 year old group 
(91\%).

The distribution of undergraduate and graduate students by gender is similar. Women in the undergraduate students group slightly overweight men as a percentage $(51.9 \%$ women vs. $48.1 \%$ men) and so do women in the graduate students group (53.4\% women vs. $46.6 \%$ men). In terms of family status, the majority of undergraduate students are single $(98.2 \%)$, as are those of the graduate students $(87.75 \%)$. The percentage of married students slightly grows as students get older ( $0.8 \%$ of undergraduates vs. $12.25 \%$ of the graduates).

The expected level of education of students in the two groups is very similar, as the medical training in the country follows secondary education and upon graduation, ends by awarding a master's degree. Therefore, the large percentage of both undergraduate and graduate respondents have completed secondary education $(97.9 \%$ vs. $95.7 \%)$, while a small percentage in both groups have a bachelor's degree $(1.3 \%$ vs. $2.4 \%)$ or a master's degree $(0.8 \%$ vs. $1.9 \%)$.

The study used a descriptive research design. Both descriptive and inferential statistics were used for the purposes of the study. The data were analyzed using descriptive statistics (charts, frequency counts and percentages). Tables and graphs illustrate the results.

\subsection{Results and Discussion}

The comparative analysis of the survey results of the respondents in the two groups reveals the trends in their needs and opinions for enhancing verbal communication skills.
Regarding the factors of physician-patient communication, the survey shows changes in students' attitudes while students deepen and expand their experience during their medical theoretical and practical training. As students get more professional training, they become aware that some factors have a greater impact on physician-patient communication. An increase is detected in the significance of the factor "patient's mental and emotional state" (from 79.3\% with the undergraduates group to $90.2 \%$ with the graduates group) and the factor "patient's educational level" (from $48.7 \%$ to $62.7 \%$ ). There is also a significant increase in the percentage revealing the significance of the factor "the physician's use of appropriate verbal communication techniques" (from 71.8\% with undergraduates to $87.2 \%$ with graduates). More graduates $(62.7 \%)$ than undergraduates $(59.4 \%)$ consider that the patient's age is a significant factor in physician-patient communication. A decrease is noted in the importance of the factor "physician's opportunity to allocate sufficient time to communication" (from $64.2 \%$ with the undergraduates to $57.8 \%$ with the graduates). Discussions with the graduates revealed they had realized that despite the great workload the physician should always find enough opportunities for dialogue with the patient and allocating time to dialogue with patients should be considered not merely a factor but an imperative. As a whole, all respondents recognize the significance of the factors of physician-patient communication, which concern both participants in the rapport. With the increase of their medical training students become more aware it is crucial to allocate sufficient time to communicate with the patient.

Table 1. Factors of physician-patient communication according to undergraduate and graduate students.

\begin{tabular}{|c|c|c|c|c|c|c|}
\hline & $\begin{array}{l}\text { Patient's } \\
\text { age }\end{array}$ & $\begin{array}{l}\text { Patient's } \\
\text { educational } \\
\text { level }\end{array}$ & $\begin{array}{l}\text { Patient's mental and } \\
\text { emotional state }\end{array}$ & $\begin{array}{l}\text { Physician's opportunity } \\
\text { to allocate sufficient time }\end{array}$ & $\begin{array}{l}\text { Physician's use of adequate } \\
\text { verbal communication } \\
\text { techniques }\end{array}$ & Other \\
\hline Undergraduate students & $59.4 \%$ & $48.7 \%$ & $79.3 \%$ & $64.2 \%$ & $71.8 \%$ & $5.1 \%$ \\
\hline Graduate students & $62.7 \%$ & $62.7 \%$ & $90.2 \%$ & $57.8 \%$ & $87.2 \%$ & $6.9 \%$ \\
\hline
\end{tabular}

As regards problems in the physician-patient communication, the highest percentage of undergraduate students pointed out that the most important problems are "ignoring patients' social and cultural specificity" (64.9\%) and "insufficient time allocated to communication" (61.8\%). The graduate respondents emphasized the problems "physician's insufficient communication skills" (87.2\%) and "insufficient time allocated to communication" (79.9\%). This shows graduate students are increasingly focusing on how the doctor will cope with communicative situations. It is important to point out that graduates have indicated more problems in the physician-patient communication in comparison to undergraduates (2.43 responses given by undergraduates vs. 3.29 responses by graduates). In general, the large number of problems in physician-patient communication, which medical students have identified, suggests a growing need for communication training.

Table 2. Problems in the physician-patient communication according to undergraduate and graduate students.

\begin{tabular}{|c|c|c|c|c|c|c|}
\hline & $\begin{array}{l}\text { Physician's } \\
\text { insufficient } \\
\text { communication skills }\end{array}$ & $\begin{array}{l}\text { Patient's insufficient } \\
\text { communication skills }\end{array}$ & $\begin{array}{l}\text { Ignoring patient's } \\
\text { social and cultural } \\
\text { specificity }\end{array}$ & $\begin{array}{l}\text { Ignoring disease's } \\
\text { impact on the } \\
\text { patient }\end{array}$ & $\begin{array}{l}\text { Insufficient time } \\
\text { allocated to } \\
\text { communication }\end{array}$ & Other \\
\hline $\begin{array}{l}\text { Undergraduate } \\
\text { students }\end{array}$ & $57 \%$ & $49.8 \%$ & $64.9 \%$ & $4.8 \%$ & $61.8 \%$ & $4.1 \%$ \\
\hline $\begin{array}{l}\text { Graduate } \\
\text { students }\end{array}$ & $87.2 \%$ & $52.9 \%$ & $73.5 \%$ & $31.8 \%$ & $79.9 \%$ & $4.9 \%$ \\
\hline
\end{tabular}

Future physicians were also asked if they agreed that enhancing their communication skills was important. It has become clear that the more knowledge and practice of their profession they get, the more they understand that communicating with patients is vital to their success as doctors. The students who chose responses at the positive end of the spectrum (the sum of "agree" and "strongly agree" responses) rise from $77.6 \%$ in the undergraduate group to $87.7 \%$ in the graduate group. 


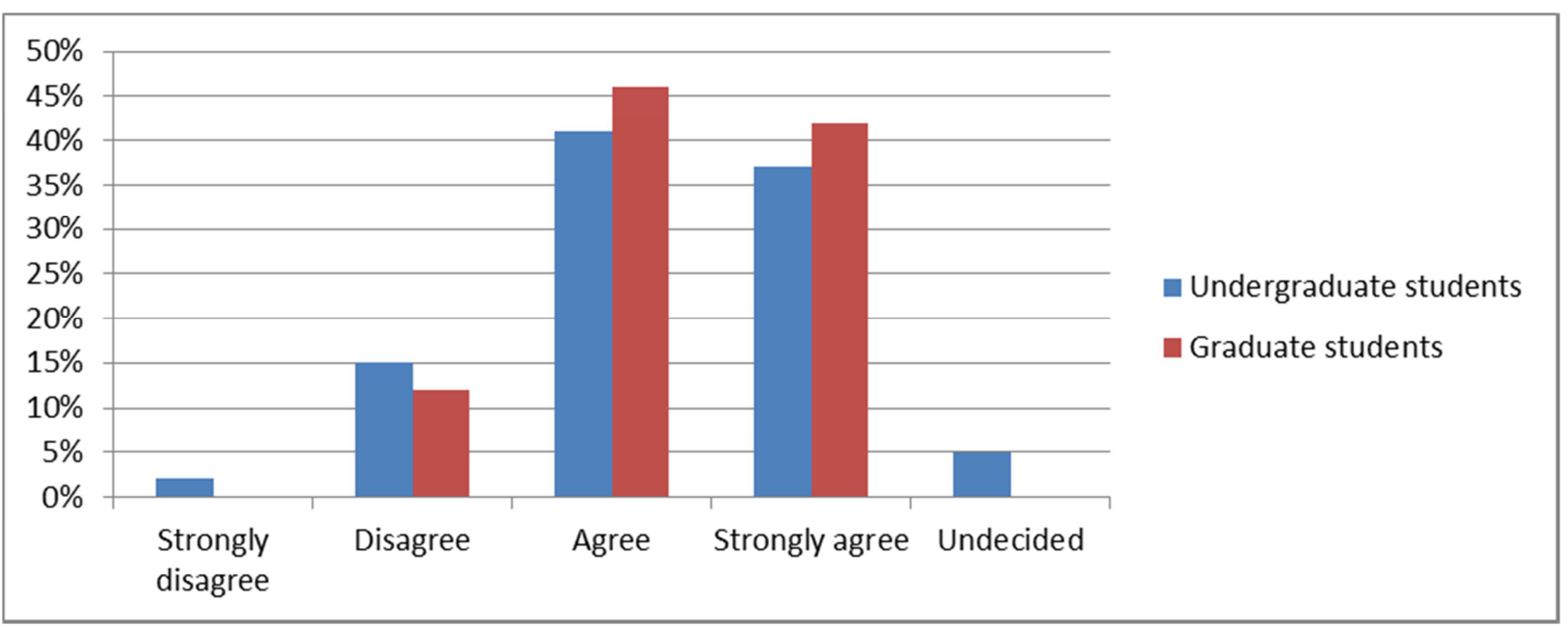

Figure 1. Importance of enhancing verbal communication skills for communication with patients according to undergraduate and graduate students.

More than one response could be chosen when answering the question about the ways to improve physician-patient verbal communication. On the average, graduate students have chosen more responses than the undergraduate (4.2 responses from graduates vs. 3.87 responses from undergraduates). That clarifies that as medical students approach their graduation, their interest in enhancing their communication skills grows. The largest increase in the percentage of graduates' responses compared to undergraduates' ones is observed in the following methods of improving communication: using appropriate language techniques (from $69.4 \%$ with undergraduates to $82.8 \%$ with graduates, showing an increase of $13.4 \%$ ), clear explanations (from $69 \%$ to $79.9 \%$, showing an increase of $10.9 \%$ ) and abiding by the principles of good behavior (from $87.9 \%$ to $98 \%$, showing an increase of $10.1 \%$ ). The increase in the percentage of the first two responses implies that students are aware the good command of different communication techniques is crucial for successful dialogue with patients.

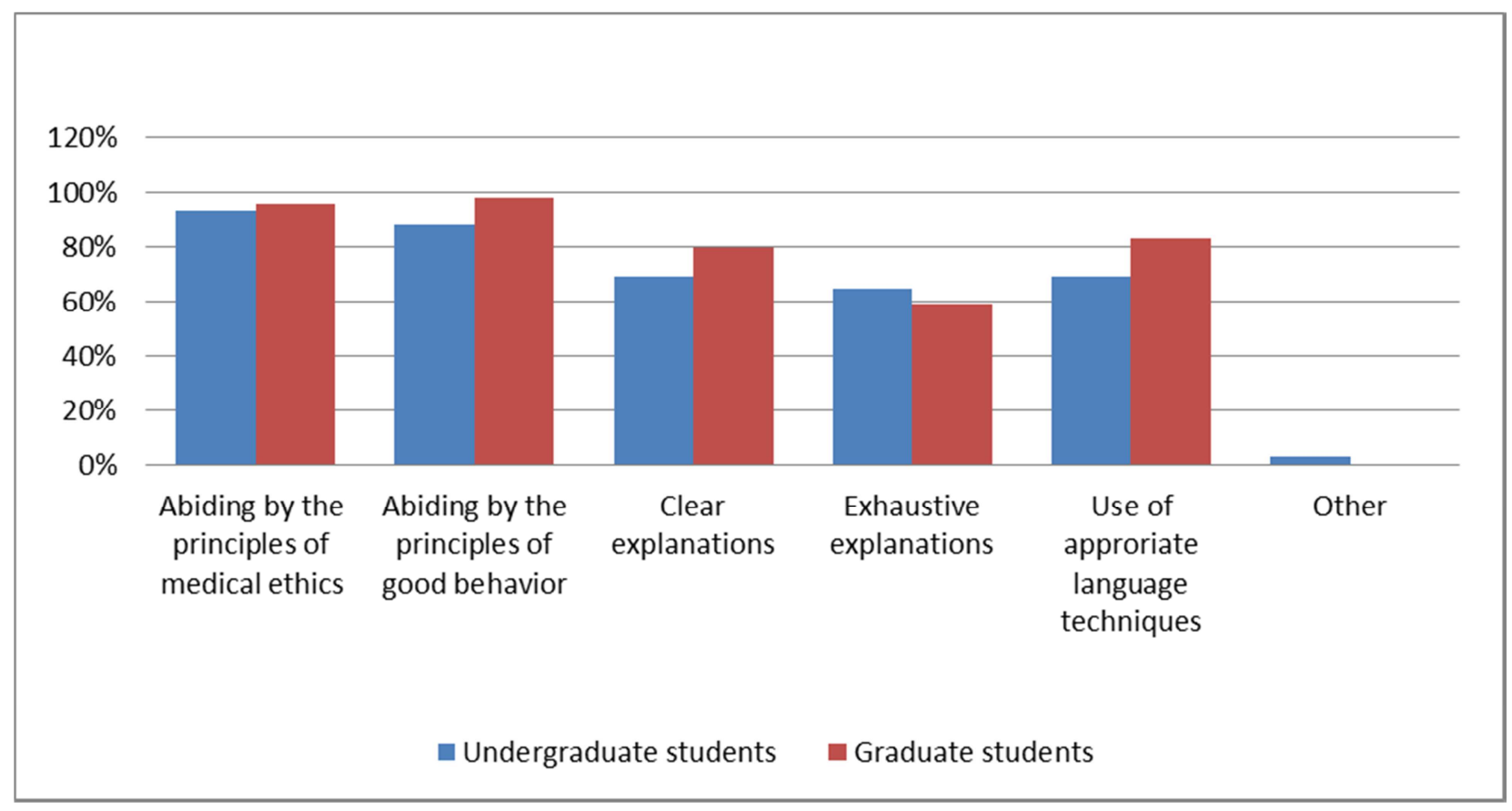

Figure 2. Ways to improve physician-patient communication according to undergraduate and graduate students.

When asked if they need to develop their communication skills, most undergraduates chose the response "agree" (51.6\%) and most graduates - "strongly agree" (58.8\%). The percentage of those, who are undecided, declines from $3.4 \%$ with undergraduates to $1 \%$ with graduates. These data are a clear indicator that although communication courses at Medical University-Sofia are mainly taught to undergraduates, it is graduates who are more aware of their need to pass such courses and increase their verbal communication skills. 


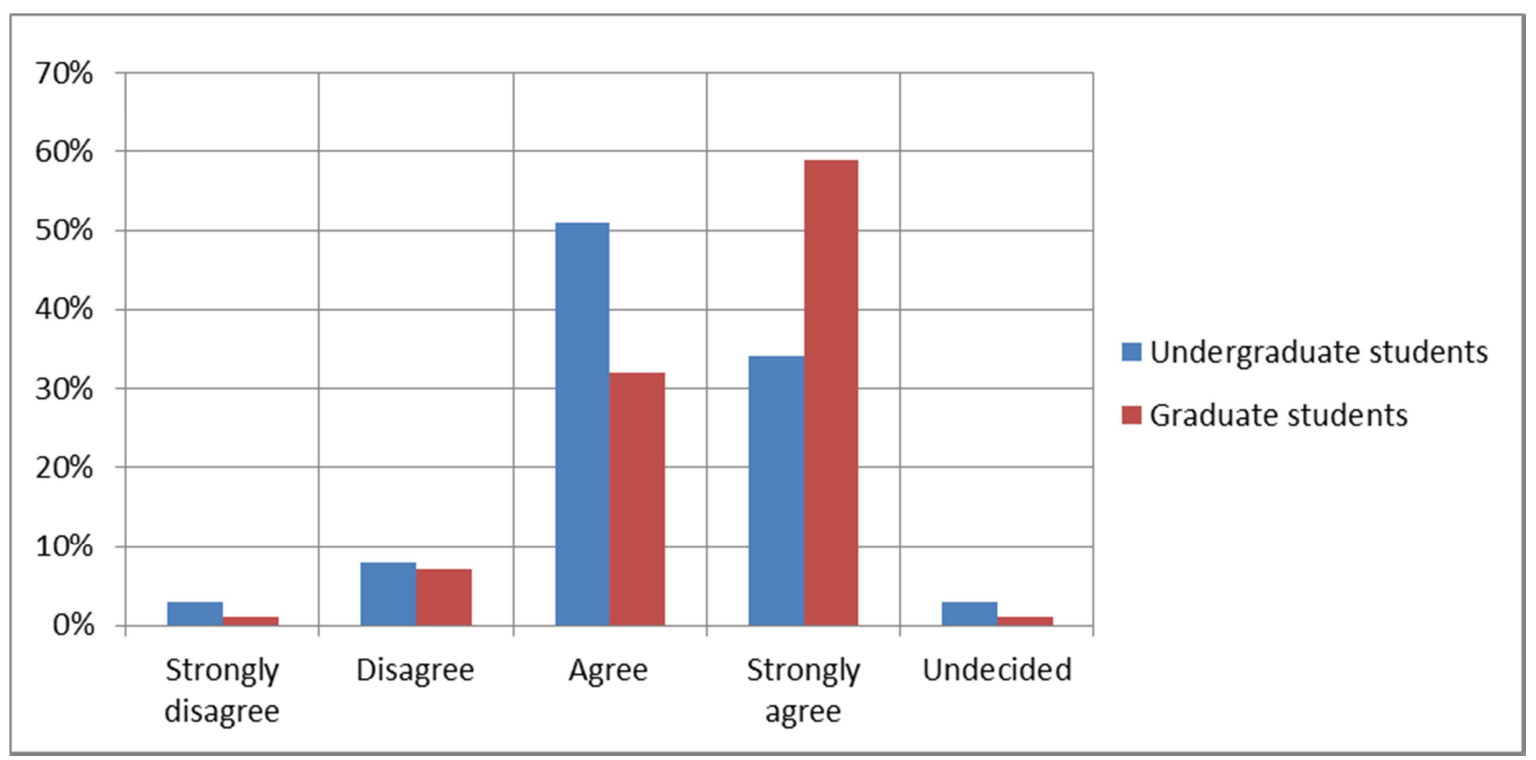

Figure 3. Need for developing verbal communication skills according to undergraduate and graduate students.

Further, we proceed to examine the extent to which there is a conscious willingness in students to prepare for communication with patients. The respondents in both groups express a clear willingness to work on improving their communication skills with their determination growing with time and experience. The majority of responses, given by undergraduates, are "agree" (42.5\%), while those, chosen by the graduates, are "strongly agree" (52.9\%).

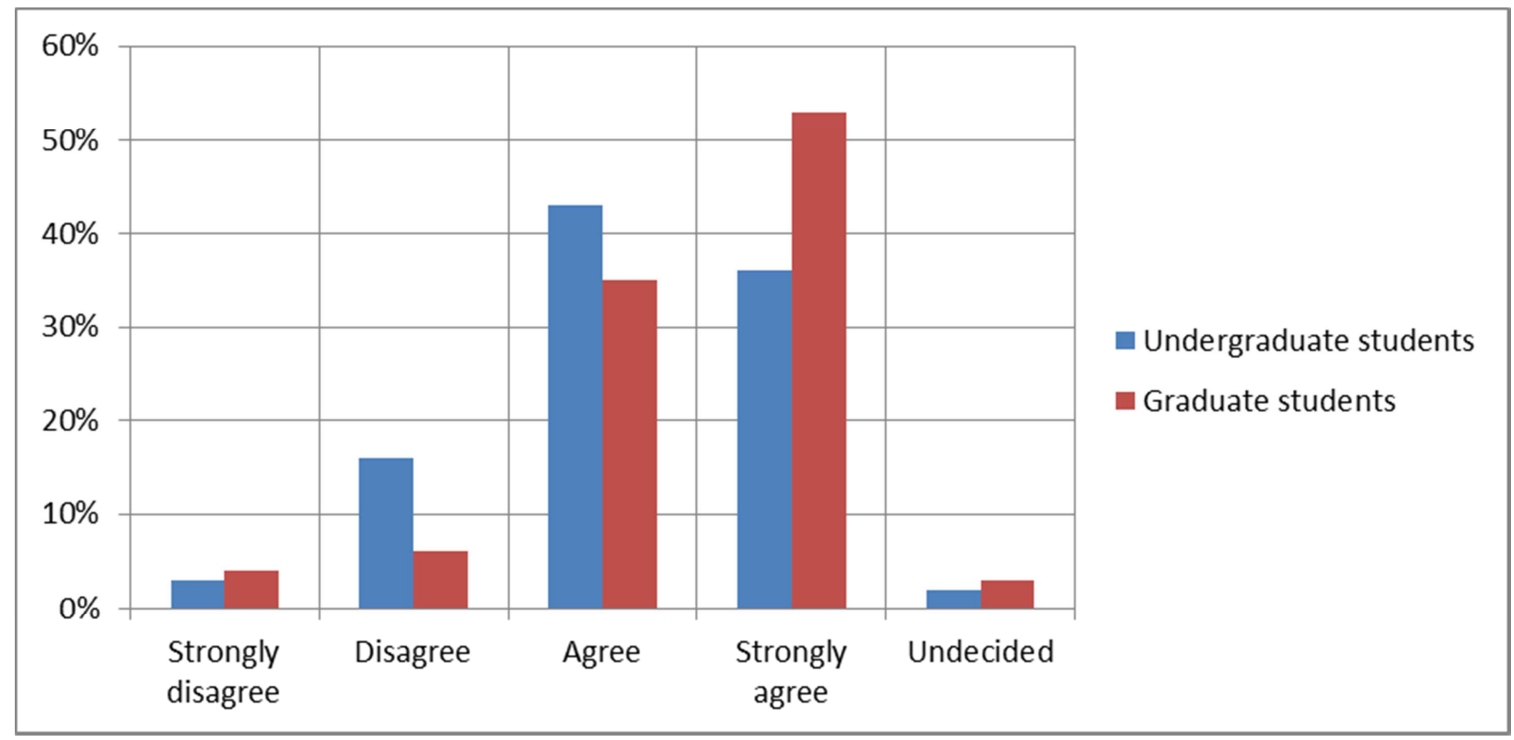

Figure 4. Willingness to increase verbal communication skills according to undergraduate and graduate students.

The comparison of the survey results of undergraduate and graduate students reveals the trends in preferred learning methods to enhance verbal communication skills. Graduate students are convinced that communication courses should include a lot of practical tasks. The questionnaire data indicate that by choosing a positive response ("strongly agree" or "agree"), $89.2 \%$ of the graduate students definitely support practical tasks during the communication course. The majority of both graduate and undergraduate students $(82.8 \%$ of graduates and $78 \%$ of undergraduates) favor group work, as they realize that dialogues, discussions and other group activities can best prepare them for building rapport with patients. The results reveal that group learning methods, used in communication courses for undergraduates at Medical University-Sofia, can also be used in courses with graduate students.

In both groups the desire for role-play simulations, characterized by their authentic and realistic nature $(77.9 \%$ of graduates responses and $57.5 \%$ of undergraduates responses), dominates over other types of group work $(8.9 \%$ of graduates responses and $22 \%$ of undergraduates responses) and individual tasks $(13.2 \%$ of graduates responses and $20.5 \%$ of undergraduates responses). Graduates' increasing focus on role play, based on medical cases and situations (77.9\%), indicates they realize they should already have well-developed professional communication skills and competencies, when they start their career as physicians. 


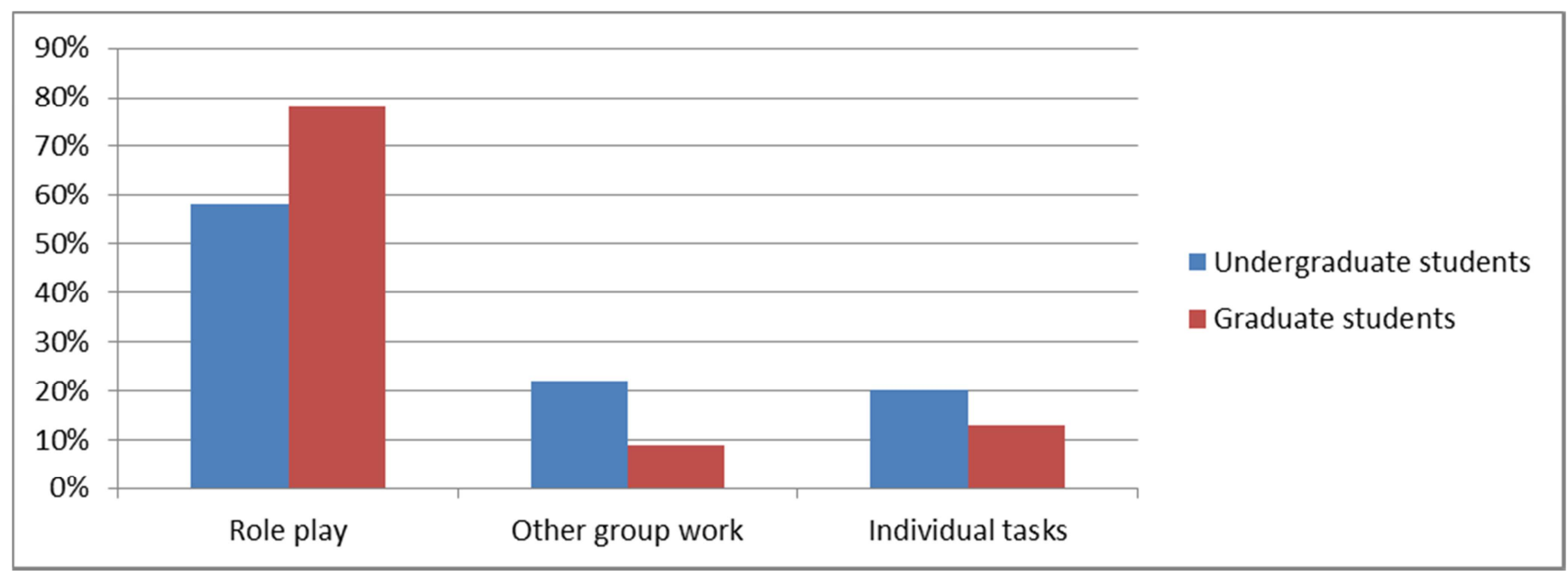

Figure 5. Preference for role play according to undergraduate and graduate students.

To conclude, given the findings of this needs analysis, it can be maintained that medical students at Medical University-Sofia perceive a growing need to improve verbal communication skills, emphasize the importance of patient-physician communication, detect different ways to increase communication skills through targeted training, and choose practical tasks, group work and realistic role play as preferred learning methods. The needs and willingness to enhance verbal communication skills are well pronounced with undergraduates and grow even more with graduates.

\section{Model for Enhancing the Verbal Communication Skills of Future Physicians}

The study of the needs of medical students at the Medical University-Sofia revealed the high level of awareness, willingness and determination of students to improve their verbal communication skills. Based on the communication skills for medical education, outlined in the European and global experts' consensus statements, the research-based language techniques, used in relation with Council Directive 93/13 / EEC of 5 April 1993 and the needs analysis for improving the communication skills of medical students at Medical UniversitySofia, a Model for enhancing the verbal communication skills of future physicians with patients can be designed. Both literature and needs analysis indicate that the relevant features, which can be employed to design the Model, are the stages of verbal communication during medical examination and treatment, addressed in the consensus statements, and the language techniques, developed for the Clear writing and plain language campaign. The stages of medical communication, which we adopt on the basis of the consensus statements, are as follows: a) build the physician-patient relationship; b) open the discussion; c) gather information; d) understand the patient's perspective; e) share information; f) reach agreement on problems and plans; g) provide closure; h) manage rapport (placed along the horizontal axis). The language techniques for understandable and plain language expression, elaborated and used in the European Clear writing campaign and applied in our Model, are as follows: 1 . paraphrase, 2. change the time frame, 3. explore the consequences, 4 . give a short and simple presentation, 5. find a counter-example, 6. create an active attitude, 7. appeal to positive intentions, 8. change the context, 9. avoid complex terminology (placed along the vertical axis). Here we present the Model.

Table 3. Model for enhancing the verbal communication skills of future physicians.

\begin{tabular}{|c|c|c|c|c|}
\hline $\begin{array}{l}\text { Stages of verbal communication/ } \\
\text { Language techniques }\end{array}$ & $\begin{array}{l}\text { a) build the physician- } \\
\text { patient relationship }\end{array}$ & b) open the discu-ssion & $\begin{array}{l}\text { c) gather infor- } \\
\text { mation }\end{array}$ & $\begin{array}{l}\text { d) understand the patient's } \\
\text { perspective }\end{array}$ \\
\hline 1.paraphrase & 1.a & $1 . b$ & 1.c & 1.d \\
\hline 2.change the time frame & 2.a & 2.b & 2.c & 2.d \\
\hline 3.explore the consequences & 3.a & 3.b & 3.c & 3.d \\
\hline 4.give a short and simple presentation & 4.a & 4.b & 4.c & 4.d \\
\hline 6.create an active attitude & $6 . \mathrm{a}$ & $6 . b$ & $6 . c$ & $6 . d$ \\
\hline 7.appeal to positive intentions & 7.a & 7.b & 7.c & 7.d \\
\hline 8.change the context & 8.a & 8.b & 8.c & 8.d \\
\hline 9.avoid complex terminology & 9.a & $9 . b$ & 9.c & 9.d \\
\hline
\end{tabular}


Table 3. Continued.

\begin{tabular}{|c|c|c|c|c|}
\hline $\begin{array}{l}\text { Stages of verbal communication/ } \\
\text { Language techniques }\end{array}$ & e) share infor-mation & $\begin{array}{l}\text { f) reach agreement on } \\
\text { problems and plans }\end{array}$ & g) provide closure & h) manage rapport \\
\hline 1.paraphrase & 1.e & 1.f & $1 . \mathrm{g}$ & 1.h \\
\hline 2.change the time frame & 2.e & 2.f & 2.g & 2.h \\
\hline 3.explore the consequences & 3.e & 3.f & $3 . g$ & 3.h \\
\hline 4.give a short and simple presentation & 4.e & 4.f & $4 . \mathrm{g}$ & 4.h \\
\hline 6.create an active attitude & 6.e & $6 . f$ & $6 . \mathrm{g}$ & 6.h \\
\hline 7.appeal to positive intentions & 7.e & 7.f & 7.g & 7.h \\
\hline 8.change the context & 8.e & $8 . f$ & $8 . \mathrm{g}$ & 8.h \\
\hline 9.avoid complex terminology & 9.e & 9.f & $9 . \mathrm{g}$ & 9.h \\
\hline
\end{tabular}

The Model reveals that each language technique can be used in communication at any stage of medical communication. Thus, a large number of plain and understandable language expressions can be produced that are adapted to one or another communicative situation in medical practice.

Based on a physician's phrase from a conversation with a patient, we can show how, using the Model, a phrase can vary and improve by applying the appropriate language techniques so that it is best adapted to a particular medical communication situation. The example uses the physician's phrase "We'll do everything possible to make you feel better", related to "Build the physician-patient relationship" stage of verbal communication. Each line in the example indicates the technique, following is the source phrase and finally, one of the possible phrases, which is the result of using that technique and aimed at building good physician-patient relationships. Here is the example:

Table 4. Example of applying the language techniques to "Build the physician-patient relationship" stage of verbal communication.

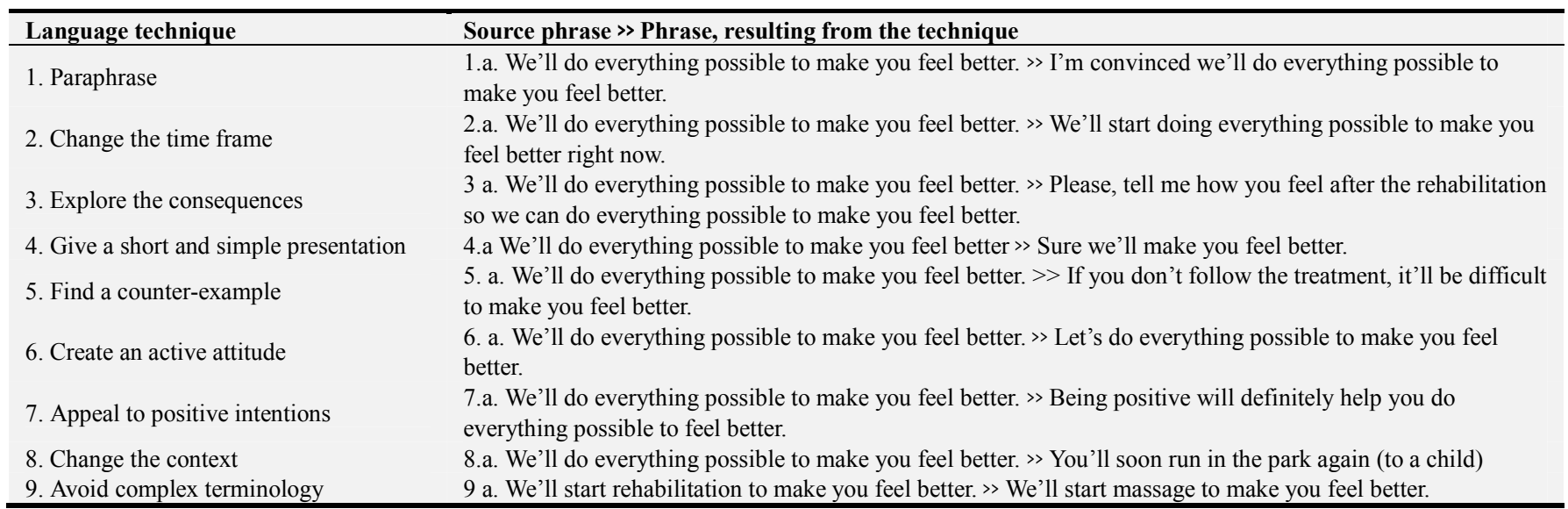

The Model demonstrates possible variations of language expressions, used in the medical communication situations. For future physicians, it is crucial to learn how to use this language variability in communicating with patients during different stages of medical examination and taking into account the specific communicative situation.

\section{Expert Assessment of the Model for Enhancing the Verbal Communication Skills of Future Physicians}

The Model for enhancing the verbal communication skills of future physicians has been subject to a validation process by a Delphi expert panel. The process included literature review, assessment using a questionnaire and discussions. The questionnaire aimed at rating the importance of the
Model's relevant features, namely, the stages of medical communication and language techniques for physicianpatient communication. It contains closed-ended questions with a range of response options, representing levels of importance and designed on a 5-point Likert scale. It ends with an open-ended question which helped collect additional information on the significance, practical application, strengths and threats in the use of the Model.

The panel included 20 experts who are researchers and lecturers/teachers in the field of teaching verbal communication skills, medical pedagogy, medical psychology, social medicine, public health, ethics and bioethics to medical students. The expert panel includes 10 professors, 7 associate professors, one assistant professor, a $\mathrm{PhD}$ holder and a lecturer who come from university and research centers in Bulgaria and other EU countries. 


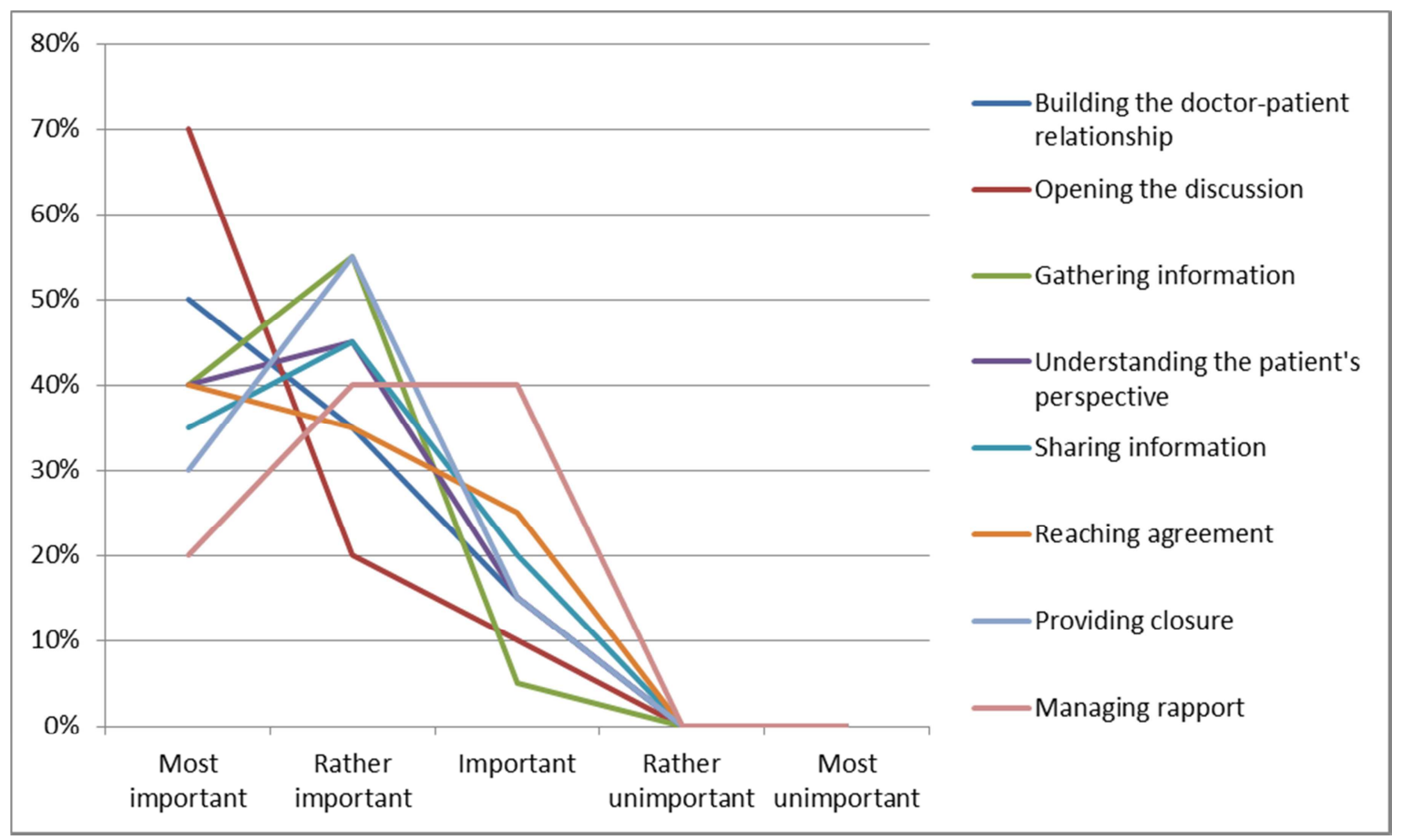

Figure 6. Rating the importance of the stages of medical communication as elements of the Model according to the expert panel.

When experts analyzed the importance of the different stages of medical communication as elements of the Model, they gave a positive assessment by rating all stages as "most important", "rather important" or "important". None of the stages in the Model is defined by an expert as irrelevant to any degree. The stage of "opening the discussion" with the patient, which represents the beginning of building rapport and creating trust, is determined as the "most important"
( $70 \%$ of all responses on this stage). The stages of "gathering information" and "drawing conclusions" (55\% of responses "rather important" on each of the stages) are considered of particular importance. The "managing rapport" stage has gathered the lowest level of acceptance, which experts explain with the increasing focus on greater equality in the physician-patient relationship and the decrease of the physician's role in directing rapport.

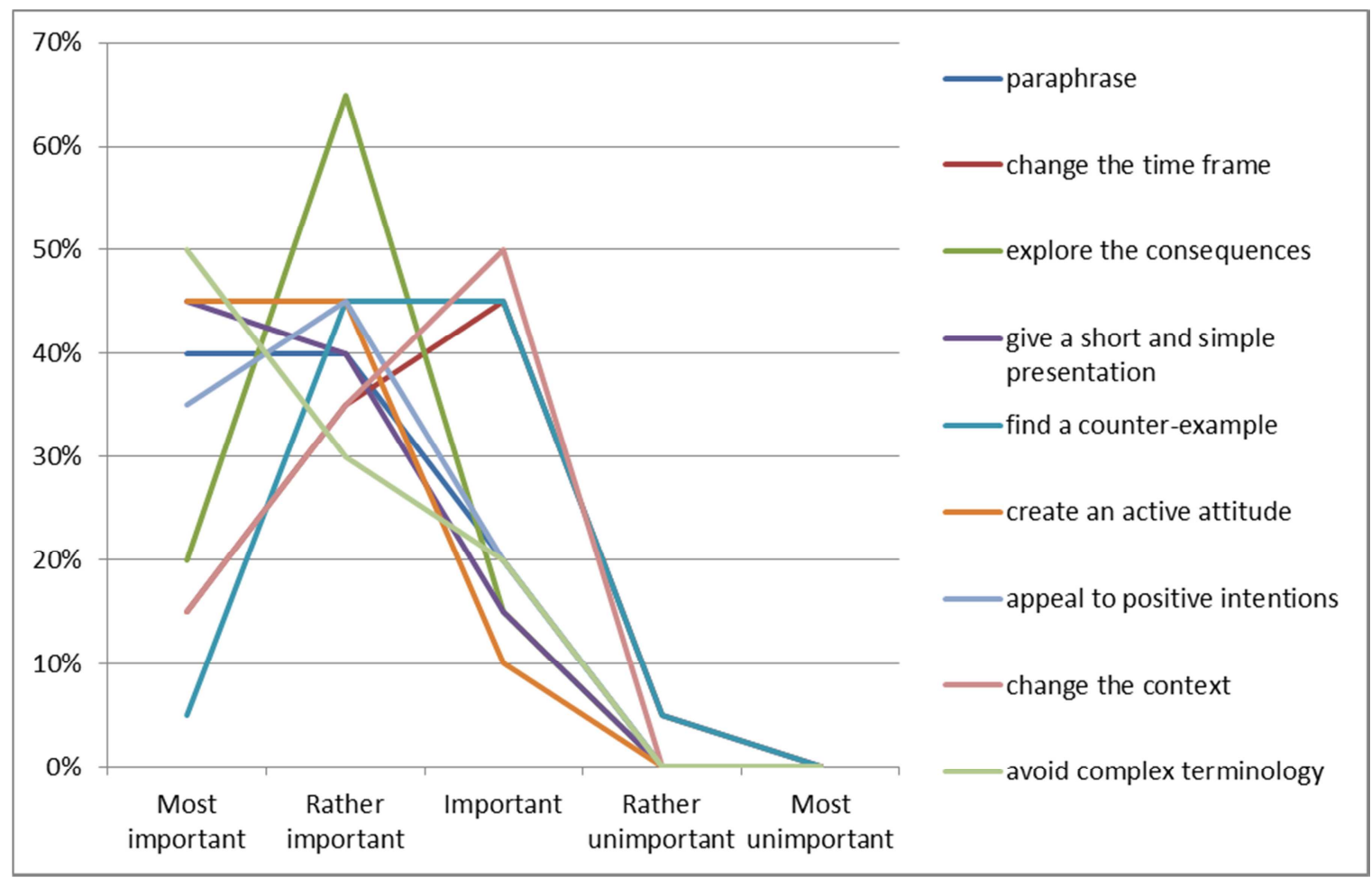

Figure 7. Rating the importance of the language techniques for verbal communication as elements of the Model according to the expert panel. 
When assessing each language technique for verbal communication on the 5-point Likert scale, the highest percentage of experts $(50 \%)$ rate the technique "avoid complex terminology" as "most important". The techniques "create an active attitude" and "give a short and simple presentation" were rated as "most important" by the second highest percentage of experts ( $45 \%$ for each technique). Experts agree that the technique "avoid complex terminology", which has long been applied, facilitates communication with patients and improves patient's understanding and treatment compliance. "Creating an active attitude" has also proven its effectiveness in relation to the strong tendency to engage all of the patient's strengths and abilities to achieve the best treatment outcomes. Experts state "giving a short and simple presentation" of thoughts helps the patient focus on the key items in the doctor's message.

Although the experts' responses regarding the significance of language techniques are predominantly positive (from "most important" to "important"), the techniques "find a counter-example" and "change the time frame" have been rated as "rather unimportant" by one expert. The expert's arguments are related to the recommended use of these techniques only in certain communicative situations and in certain medical cases when they will not cause negative emotions and thus, harm the patient. Hence, it is crucial that the techniques "find a counter-example" and "change the time frame" should be used in conjunction with the technique "change the context". This suggests that language techniques are best used as a complex, thus, mutually reinforcing their influence.

The open-ended question gives information about the strengths of the Model, which is determined by experts as an innovative and integrational approach to patient-physician communication, an adequate tool to enhance future physicians' communication skills and thus, helps to enhance the quality of patient health care and increase patient satisfaction. Experts emphasize the Model opens up opportunities for further research on the interrelation of each communication stage with the language techniques, on key language expressions with widespread use in doctor-patient communication, on its application in different circumstances of medical communication. The weaknesses, the experts perceive in the Model, are related to its limitations, determined by the fact that it is based on the needs analysis of concrete students with concrete learning needs. The threats in using the Model, indicated by the experts, are connected to a chance of inappropriate choice and use of a language technique. Experts recommend that the Model become part of the communication training curriculum of the Medical University-Sofia and of medical schools with a similar learning needs profile of their medical students. In general, experts express their positive opinion of the Model for enhancing the verbal communication skills of future physicians and an interest in the results of its further development and implementation.

\section{Conclusion}

Teaching communication for the purposes of the medical profession is a central problem of medical education. Therefore, medical schools and experts have sought consensus on outlining communication training curricula and a set of communication skills, which medical students are to acquire.

The present study reveals the relationship between the stages of physician-patient communication and the language techniques for professional communication, on the one hand, and the concrete learning needs of the medical students at the specific medical school, on the other hand. Based on the findings of the needs analysis, it was concluded that the medical students at the Medical University-Sofia identify an array of problems in physician-patient communication and perceive a complex of factors with an impact on medical communication. They are aware of the importance of verbal communication skills for their future professional practice and demonstrate willingness and readiness to enhance these skills through leaning methods such as group work and role play. The survey reveals that undergraduates express their well-defined needs, willingness, positive attitudes and conviction to enhance their verbal communication skills which grow even stronger with graduates.

To meet medical students' needs and to help train students for their professional communication, we have designed a Model for enhancing medical students' verbal communication skills, based on communication research and expertise. On the one hand, the Model is based on the consensus statements of communication training experts, who have analyzed the stages of physician-patient communication and outlined major skills and communication curricula to be taught. On the other hand, the language techniques for enhancing medical students' communication skills are derived from the Clear writing and plain language campaign, dealing with professional communication. The designed Model is meant to be applied in meeting the learning needs and expectations of medical students at the Medical University-Sofia.

\section{Recommendations}

Based on the present research, the following recommendations can be formulated:

1. As graduate students show a growing need and willingness for communication training, the management of the Medical University should complement communication training courses for undergraduates with more opportunities for communication training for graduate students.

2. The Model to enhance medical students' verbal communication skills, based on the stages of medical communication and language techniques, should be applied in the communication training curriculum of the Medical University-Sofia. 


\section{References}

[1] Frymoyer JW and Frymoyer NP (2002) Physician-patient communication: a lost art? J Am Acad Orthop Surg. 2002 Mar-Apr; 10 (2): 95-105.

[2] Makoul G and Schofield T. Communication teaching and assessment in medical education: an international consensus statement. Netherlands Institute of Primary Health Care. Patient Educ Couns 1999; 37: 191-5.

[3] Hochman O, Itzhak B, Mankuta D. and Vinker S. (2008) The relation between good communication skills on the part of the physician and patient satisfaction in a military setting. Mil Med. 2008 Sep; 173 (9): 878-81.

[4] Zolnierek KB and Dimatteo MR. (2009) Physician communication and patient adherence to treatment: a metaanalysis. Med Care. 2009 Aug; 47 (8): 826-34. doi: 10.1097/MLR.0b013e31819a5acc.

[5] Bioethics Core Curriculum. Division of Ethics of Science and Technology. Sector for Social and Human Sciences. UNESCO

[6] Boniolo G. and V. Sanchini. (2016), Ethical Counselling and Medical Decision-Making in the Era of Personalised Medicine: A Practice-Oriented Guide, Springer, 117 p.

[7] Borisov, V. (2008) Healthcare reform at a crossroads- chaos and management. $140 \mathrm{c}$.

[8] Vodenicharov, Ts. and S. Popova (2009), [Social medicine], Sofia, $237 \mathrm{c}$.

[9] Haak R1, Rosenbohm J, Koerfer A, Obliers R. and Wicht MJ. (2008) The effect of undergraduate education in communication skills: a randomised controlled clinical trial. Eur J Dent Educ. 2008 Nov; 12 (4): 213-8. doi: 10.1111/j.1600-0579.2008.00521.x.

[10] Tanaka N1, Maruyama M, Amagai A, Saotome K, Tomikawa E, Michiyama K, Kondo S, Tanaka H, and Sato H. (2008) [Development and evaluation of communication skills learning suitable for community pharmacy]. Yakugaku Zasshi. 2008 Jan; 128 (1): 97-110.

[11] Bonvicini KA1, Perlin MJ, Bylund CL, Carroll G, Rouse RA and Goldstein MG. (2009) Impact of communication training on physician expression of empathy in patient encounters. 74 . Patient Educ Couns. 2009 Apr; 75 (1): 3-10. doi: 10.1016/j.pec.2008.09.007. Epub 2008 Dec 10.

[12] Association of American Medical Colleges. (1999) Report III Contemporary Issues in Medicine: Communication in Medicine. Medical School Objectives Project October 1999.

[13] Balkanska, P. (2014), [Applied psychology in medical practice], Bulvest 2000, Sofia.

[14] Simpson M, Buckman R, Stewart M, Maguire P, Lipkin M, Novack D, et al. Doctor-patient communication: the Toronto consensus statement. Brit Med J, 1991; 303: 1385-7.

[15] The Health Professionals Core Communication Curriculum (HPCCC): Objectives for undergraduate education in health care professions. $\mathrm{http} / / / \mathrm{www} . e a c h . e u / \mathrm{wp}-$ content/uploads/2014/07/HPCCC_website-tEACH.pdf

[16] Van Thiel J, Ram P and van Dalen J. MAAS-Global 2000.
Netherlands: $\quad$ Maastricht $\quad$ University; 2000, http://www.hag.unimaas.nl/maasglobal_2000/GB/MAASGlobal-2000-EN.pdf.

[17] Makoul G. Essential elements of communication in medical encounters: the Kalamazoo consensus statement. Acad Med, 2001; 76: 390-3.

[18] Von Fragstein M, Silverman J, Cushing A, Quilligan S, Salisbury $\mathrm{H}$ and Wiskin C. UK Council for Clinical Communication Skills Teaching in Undergraduate Medical Education. UK consensus statement on the content of communication curricula in undergraduate medical education. Med Educ 2008; 42, 1100-7.

[19] Kiessling C, Dieterich A, Fabry G, Holzer H, Langewitz W, Mullinghaus $\mathrm{M}$, et al. Communication and social competency in medical education in German speaking countries: the Basel consensus statement. Results of a Delphi Study. Patient Educ Couns, 2010; 81: 259-66.

[20] Council of Europe, Council for Cultural Co-operation. Education Committee. Modern Languages Division. (2001) Common European Framework of Reference for Languages: Learning, Teaching, Assessment, Strasburg, Cambridge University Press, $260 \mathrm{p}$.

[21] Dudeva, B. (2009) Methodological aspects of the Lexical approach in teaching English to medical students. Sofia. St. Kliment Ohridski University Press.

[22] Bygate, M., P. Skehan and M. Swain (2001) Researching Pedagogic Tasks. Second Language Learning, Teaching and Testing. Harlow. Pearson Education Ltd.

[23] Davies, P. and E. Pearse (2000) Success in English Teaching. Oxford. Oxford University Press.

[24] Deller, Sh. and Ch. Price (2007) Teaching Other Subjects Through English. Oxford University Press.

[25] Glendinning, E. H. (2007) Professional English in Use. Medicine 1 st Edition. Cambridge University Press, $176 \mathrm{p}$.

[26] Allum, V. (2012) English for Medical Purposes: Doctors, lulu.com, $266 \mathrm{p}$.

[27] Salager-Meyer F. Origin and development of English for Medical Purposes. Part I: Research on written medical discourse. Medical Writing 2014; 23 (1): 46-48.

[28] Widdowson, H. G. (2007) Discourse Analysis. Oxford. Oxford University Press.

[29] Gotti M and Salager-Meyer F. (2006) Advances in medical discourse analysis: oral and written contexts. Bern: Peter Lang.

[30] Wodak, R. (2006). Medical discourse: doctor-patient communication.In Brown, K. (Ed.), Encyclopaedia of language and linguistics. (pp. 681-688). Amsterdam: Elsevier.

[31] Hyland, K. (2004) Disciplinary Discourses. Ann Arbor: University of Michigan Press.

[32] Field, Z. (2012), How to write clearly. European Commission. Directorate-General for Translation.

[33] Matarese V. (2012), Supporting Research Writing: Roles and Challenges in Multilingual Settings, Elsevier, $330 \mathrm{p}$.

[34] Strickland, P. The European Commisssion's Clear Writing Campaign, Clarity 65, 2011: 14-16. 
[35] Directorate General for Translation. (2010), Clear writing. http://ec.europa.eu/dgs/translation/publications/magazines/lan guagestranslation/documents/issue_01_en.pdf.

[36] Council Directive 93/13/EEC of 5 April 1993 on unfair terms in consumer contracts. 21.4.1993, Official Journal of the European Communities, L 95/29, Art.2, Art.5.

[37] Mac Aodha, M. (2016), Legal Lexicography: A Comparative Perspective. Routledge, $360 \mathrm{p}$.

[38] Mattila, H. E. S. (2013), Comparative Legal Linguistics: Language of Law, Latin and Modern Lingua Francas. Ashgate Publishing, Ltd., 504 p.

[39] Claire's Clear Writing Tips, https://ec.europa.eu/info/sites/info/files/clear_writing_tips_en. pdf.

[40] Directorate-General for Translation (European Commission). (2012), How to write clearly. 16 p.

[41] Hoekje B. J. and S. M. Tipton. (2011), English Language and the Medical Profession: Instructing and Assessing the Communication Skills of International Physicians, BRILL, $331 \mathrm{p}$.

[42] Hunt, D. And K. Harvey. Grammar and Doctor-Patient Communication. Published Online: 5 Nov. 2012, DOI: 10.1002/9781405198431.wbeal0465.

[43] MTD Training. (2012), Advanced communication skills, $1^{\text {st }}$ edition, 52 p., htpps://www.bookboon.com.
[44] Willerton R. (2015), Plain Language and Ethical Action: A Dialogic Approach to Technical Content in the 21st Century, Routledge, $222 \mathrm{p}$.

[45] European Commission. Translation and Drafting Resources, https://ec.europa.eu/info/resources-partners/translation-anddrafting-resources_en.

[46] Munby, J. (1978) Communicative Syllabus Design. Cambridge: Cambridge University Press.

[47] Chambers, F. (1980) A re-evaluation of needs analysis. ESP Journal, 1/1, pp. 25-33.

[48] Hutchinson, T., and Waters, A. (1987) English for Specific Purposes: A learning-centered approach. Cambridge: Cambridge University Press.

[49] Richterich R. (1983) Case studies in identifying language needs. Council of Europe. Pergamon Press, Oxford.

[50] Jordan, R. R. (1997) English for academic purposes. Cambridge: Cambridge University Press.

[51] West, R. (1994) Needs analysis in language teaching. Language Teaching, 27/1, 1-19.

[52] Dudley-Evans, T., and St John, M. (1998) Developments in ESP: A multi-disciplinary approach. Cambridge: Cambridge University Press. 